\title{
Soluble E-selectin in multiple sclerosis: raised concentrations in patients with primary progressive disease
}

Gavin Giovannoni, J W Thorpe, D Kidd, B E Kendall, I F Moseley, A J Thompson, G Keir, D H Miller, M Feldmann, E J Thompson

\begin{abstract}
Objective-To determine whether concentrations of soluble E-selectin (sEselectin), an immunological marker of endothelial activation, were correlated with gadolinium-DPTA enhancement on MRI in patients with multiple sclerosis. Methods-Serial sE-selectin concentrations were measured in 28 patients with multiple sclerosis undergoing monthly gadolinium (Gd) enhanced MRI of the brain and spinal cord, and in 10 control subjects. $C$ reactive protein (CRP), von Willebrand factor (vWF), and tumour necrosis factor- $\alpha$ (TNF $\alpha)$ were also determined.
\end{abstract}

Results-Primary progressive patients had significantly increased $s E$-selectin concentrations compared with the relapsing remitting and secondary progressive patients who had normal sE-selectin concentrations $(22.2 \quad(\mathrm{SD} 1 \quad 6 \cdot 1) \mathrm{ng} / \mathrm{ml} \quad v \quad 9.8$ $(\mathrm{SD2} \cdot \mathbf{1}) \mathrm{ng} / \mathrm{ml}$ and $7 \cdot 7 \quad(\mathrm{SD2} \cdot 7) \mathrm{ng} / \mathrm{ml}$, respectively, $P=0.03$ ). This difference was attributable to five of the 10 primary progressive patients who had persistently raised $s E-s e l e c t i n$ concentrations, with relatively inactive MRI studies. No correlation could be found between $\mathbf{s E - s e l e c t i n}$ concentrations and $\mathrm{Gd}$ enhancement on MRI, but a close correlation existed between mean concentrations of $\mathrm{sE}$ selectin and TNF $\alpha(r=0.71, P<0.001)$. Despite raised sE-selectin and TNF $\alpha$ concentrations, primary progressive patients had normal CRP concentrations $(1.03$ (SD1.14) mg/1), which were significantly lower than the relapsing remitting $(3 \cdot 16$ $(\mathrm{SD} 2 \cdot 54) \mathrm{mg} / \mathrm{l})$ and secondary progressive patients $(2 \cdot 28(\mathrm{SD} 2 \cdot 1) \mathrm{mg} / \mathbf{l}, P=0 \cdot 03)$. Raised CRP concentrations did correlate with infectious episodes, clinical relapse, and Gd enhancement, and were significantly raised when no MRI activity was found. Concentrations of VWF were normal in all patient groups.

Conclusions-The results further highlight the differences between patients with primary progressive and those with relapsing remitting/secondary progressive multiple sclerosis.

\section{(7 Neurol Neurosurg Psychiatry 1996;60:20-26)}

Keywords: multiple sclerosis; magnetic resonance imaging; gadolinium enhancement; E-selectin
On serial MRI of patients with relapsing remitting or secondary progressive multiple sclerosis, an early finding in most new lesions is gadolinium (Gd) DTPA enhancement. ${ }^{1}$ Evidence from chronic relapsing experimental allergic encephalomyelitis ${ }^{2}$ and multiple sclerosis $^{34}$ suggests that enhancement in these disorders indicates the presence of perivascular inflammation in which macrophages and $T$ lymphocytes predominate. ${ }^{5}$ Invasion of these macrophages and $\mathrm{T}$ lymphocytes into the perivascular space of the CNS is a complex process. ${ }^{\circ} \mathrm{A}$ model of $\mathrm{T}$ cell/endothelium interaction suggests that initial adhesion involves molecules such as the selectins and CD44, which are expressed at increased concentrations by migratory memory $\mathrm{T}$ cells. E-selectin, the most endothelial specific of the adhesion molecules, is produced by activated endothelium and its expression is induced by interleukin-1 (IL1) and tumour necrosis factor- $\alpha$ (TNF $\alpha$ ), and is augmented by interferon- $\gamma$ (INF). ${ }^{7}$ E-selectin is a member of the selectin family with a lectin-like $\mathrm{N}$-terminal domain. It exists either as a membrane bound receptor that recognises the tetrasaccharide sialylLewis $^{x}$ or sialyl-Lewis ${ }^{a}$ ligands of monocytes and granulocytes, or as a smaller soluble form (sE-selectin) that may function as a circulating inhibitor of cell adhesion." As E-selectin is produced predominantly by activated endothelium, the concentration of sE-selectin represents the degree of endothelial activation. Raised concentrations have been found in many infectious and inflammatory disease processes, including malaria, rheumatoid arthritis, primary biliary cirrhosis, polyarteritis nodosa, giant cell arteritis, scleroderma, systemic lupus erythematosus, Gram positive and Gram negative infections, and in patients with septic shock. ${ }^{9}$ Recently increased concentrations have been reported in two neurological conditions-Guillain-Barré syndrome and chronic inflammatory demyelinating polyneuropathy. ${ }^{1011}$

We hypothesised that sE-selectin concentrations, from activated endothelial cells, may correlate with Gd enhancement on MRI. A secondary hypothesis was that primary progressive multiple sclerosis, with characteristically little Gd enhancement would differ from relapsing remitting and secondary progressive disease by having low concentrations of $\mathrm{sE}$ selectin. To test these hypotheses we measured sE-selectin concentrations on various groups of patients with multiple sclerosis undergoing serial Gd enhanced MRI studies 
of the brain and spinal cord. We chose a longitudinal rather than a cross sectional study to control for any intraindividual differences and to see if sE-selectin would be of any use as a potential surrogate marker of disease activity. We also correlated concentrations of $\mathrm{sE}-$ selectin with circulating concentrations of TNF $\alpha$.

As sE-selectin is increased by many disease processes, including infections, we measured $C$ reactive protein (CRP) as a marker of the systemic acute phase response. We also measured von Willebrand factor (vWF), a multimeric protein synthesised mainly by endothelium as a marker of endothelial damage. Experimentally induced endothelial damage causes an increase in circulating concentrations of $\mathrm{vWF},{ }^{12}$ and several vasculitic diseases $^{13}$ and diabetic microangiopathy ${ }^{14}$ are associated with increased concentrations. If perivascular inflammation in multiple sclerosis causes endothelial damage vWF concentrations should be raised.

\begin{abstract}
Methods
PATIENTS

Twenty eight patients undergoing monthly MRI studies at the Institute of Neurology, London, with clinically definite or laboratory supported definite multiple sclerosis, ${ }^{15}$ were included in the study. all these patients had been recruited for a separate, independent serial MRI study, which was approved by the ethics committee of the National Hospital for Neurology and Neurosurgery. All patients had already given written informed consent. Ten patients had primary progressive multiple sclerosis, nine secondary progressive multiple sclerosis, and nine relapsing remitting disease. The diagnostic criteria of these clinical subtypes and the definitions used for defining a relapse and the period of remission in this study have been previously described. ${ }^{15}{ }^{16}$ Each patient was assessed neurologically on entry into the study and at the time of each MRI study. Disability was measured with Kurtzke's expanded disability status scale (EDSS). ${ }^{17}$ The rate of neurological deterioration for each patient was assessed by two indices; firstly the progression index, ${ }^{18}$ which is the ratio of the baseline EDSS to the duration of the disease in years, and secondly the change in EDSS per year over the study period. Any relapses, infections, or other intercurrent medical illnesses were noted as well as the use of corticosteroids or immunosuppressive agents. During each MRI study, blood was taken from an antecubital vein before giving $\mathrm{Gd}$.
\end{abstract}

\section{CONTROLS}

Serial serum samples were collected from 10 healthy volunteers, at weekly intervals for a period of two months. Control samples taken during a symptomatic infection were not included in the establishment of the normal ranges. The rationale for doing serial controls was to check for any physiological fluctuations in sE-selectin, TNF $\alpha, \mathrm{CRP}$, and vWF concentrations.
MAGNETIC RESONANCE IMAGING

All MRI studies were performed on a 1.5 Tesla Signa system (IGE Medical Systems, Milwaukee, WI). Brain MRI was carried out with a standard quadrature headcoil. Pilot images were obtained in axial, coronal, and sagittal planes to ensure adequate repositioning. Axial dual echo (proton density and T2 weighted) fast spin echo (FSE ${ }_{3500 / 18,90}$, echo train length 8) and, five minutes after the administration of Gd-DTPA (Magnevist $0.1 \mathrm{mmol} / \mathrm{kg}$, Schering), T1 weighted spin echo $\left(S_{575 / 19}\right)$ images were obtained. For both $\mathrm{T} 1$ and $\mathrm{T} 2$ weighted images contiguous interleaved $4 \mathrm{~mm}$ slices, one excitation, and a $192 \times 256$ matrix with a $24 \mathrm{~cm}$ field of view were used. Spinal imaging, with a spinal multiarray receiver coil, was carried out immediately after brain MRI. Sagittal T1 weighted spin echo images (SE ${ }_{500 / 19}, 4 \mathrm{~mm}$ contiguous interleaved slices, $256 \times 512$ matrix, $24 \times 48$ $\mathrm{cm}$ rectangular field of view, two excitations) were first obtained, about 10-15 minutes after Gd-DTPA injection. Then two sets of sagittal fast spin echo images with different degrees of T2 weighting were obtained; the parameters used were $\mathrm{FSE}_{2500 / 51}$ and $\mathrm{FSE}_{2500 / 102}$, echo train length $16,3 \mathrm{~mm}$ contiguous interleaved slices, $512 \times 12$ matrix, $48 \times 48 \mathrm{~cm}$ field of view, two excitations. The brain images were examined by one neuroradiologist (IFM) and, those of the spinal cords by another (BEK); both were unaware of the patients' clinical details. The number of individual lesions on the initial T2 weighted images were counted and graded for size to give a baseline total CNS lesion load. On subsequent examinations all contrast enhancing lesions were counted. An overall MRI activity index was calculated for each patient by dividing the total number of contrast enhancing lesions seen during the study period by the number of examinations performed.

\section{ASSAYS}

The serum and plasma samples were separated as soon as possible, coded, frozen, and stored at $-20^{\circ} \mathrm{C}$. All samples were assayed within 12 months. Repeated freeze-thaw cycles were avoided. Aliquots of serum were thawed just before use, and all assays were performed blind.

\section{SOLUBLE E-SELECTIN}

Concentrations of sE-selectin were measured by a sandwich enzyme linked immunosorbent assay (ELISA). ${ }^{19}$ The capture antibody was a mouse monoclonal anti-human E-selectin/Pselectin (BBA 1, R and D Systems Europe). The detector antibody was a biotinylated mouse monoclonal antihuman E-selectin (BBA8, R and D Systems Europe) and was conjugated to streptavidin-biotin horseradish peroxidase (HRP) complex (Amersham) before the addition of $o$-phenylene diamine (Sigma) as the enzyme substrate. The assay was calibrated primarily with purified human E-selectin (BBE 2, R and D Systems Europe) and secondarily with pooled serum from patients with active rheumatoid arthritis. The 
assay had a lower limit of detection of 0.6 $\mathrm{ng} / \mathrm{ml}$, an intraassay coefficient of variation of $4.6 \%$, an interassay coefficient of variation of $12.6 \%$, and a mean recovery of 103 (range $83-112) \%$.

\section{REACTIVE PROTEIN}

An ELISA was developed to measure concentrations of CRP less than $2 \mathrm{mg} / \mathrm{l}$. The capture antibody used was a polyclonal rabbit antihuman CRP (PC044, The Binding Site) and the detector antibody was the same HRP conjugated polyclonal rabbit anti-human CRP (PP044, The Binding Site). o-Phenylene diamine (Sigma) was also used as the enzyme substrate. Purified human CRP (GP044.L, The Binding Site) and Calibrator 7 (84403, Atlantic Antibodies) were used to calibrate the assay. The assay had a lower limit of detection of $150 \mathrm{ng} / \mathrm{ml}$, an intra-assay coefficient of variation of $6 \cdot 1 \%$, an interassay coefficient of variation of $7.9 \%$, and a mean recovery of 98 (range 92-106)\%. A commercial radial immunodiffusion assay (Nanoroid, The Binding Site) was used to determine CRP concentrations greater than $2 \mathrm{mg} / 1$.

VON WILLEBRAND FACTOR

A vWF sandwich enzyme linked immunoabsorbent assay (ELISA) was developed using a polyclonal rabbit antihuman vWF (PC054, The Binding Site), HRP conjugated polyclonal rabbit antihuman vWF (P226, Dako), $o$-phenylene diamine as the enzyme substrate and purified human vWF (GP054, Binding Site) as the calibrant. The assay had a lower limit of detection of $0.004 \mathrm{IU} / \mathrm{ml}$, an intraassay $\mathrm{CV}$ of $3.4 \%$, an interassay $\mathrm{CV}$ of $3 \cdot 1$, and a mean recovery of 95.5 (range $=$ $87-102) \%$

TUMOUR NECROSIS FACTOR- $\alpha$

Tumour necrosis factor- $\alpha$ was measured by ELISA using a previously described assay, ${ }^{20}$ with a lower limit of detection of $6-8 \mathrm{pg} / \mathrm{ml}$. Due to a shortage of samples from several patients recruited early in the course of the study $\mathrm{TNF} \alpha$ concentrations could only be assessed on 164 of the 222 samples $(74 \%)$. Only plasma collected with EDTA as the anticoagulant was used for the determination of TNF $\alpha$ concentrations, as EDTA has been shown to prevent the in vitro production of TNF $\alpha$ which may occur before the separation of the samples. ${ }^{21}$
STATISTICS

Data involving serial measurements on subjects were computed as subject means using all readings available for that particular subject. Bartlett's test for homogeneity of variance was used to test for normal distribution of data, which, if normally distributed, were compared by one way analysis of variance (ANOVA) and if not by a Kruskal-Wallis one way ANOVA. Soluble E-selectin, CRP, and $\mathrm{TNF} \alpha$ data were normalised by log transformation; therefore all statistical results reported refer to the relevant log transformations. Non-parametric data were compared by the Yates' corrected $\chi^{2}$ test and if an expected value was less than 5 Fisher's exact test was used. Simple linear regression was used to correlate concentrations of sE-selectin and $\mathrm{TNF} \alpha$. A P value $<0.05$ was considered statistically significant.

\section{Results}

BASELINE CLINICAL AND MRI DATA (TABLE 1)

Relapsing remitting patients were significantly younger than either the secondary progressive or primary progressive patients $(\mathrm{P}<0.001)$. Sex ratios of the groups differed significantly with nine of nine relapsing remitting, five of nine secondary progressive, and one of 10 primary progressive patients being female $(P<$ $0.001)$. The age of disease onset of the groups did not differ statistically. The disease duration of the relapsing remitting patients was significantly shorter than that for the secondary progressive and primary progressive patients $(P=0.009)$. The relapsing remitting patients were less disabled on entry into the study, with a median EDSS of 2.5 compared with 6 and 5.5 for the secondary progressive and primary progressive patients respectively $(P<0.001)$; no relapsing remitting patients had an EDSS $>5.5$ compared with $78 \%$ of the secondary progressive and $50 \%$ of the primary progressive patients ( $P=0.001)$. There was no significant difference between the progression index of the three groups. The baseline MRI CNS lesion load seemed lower in the primary progressive patients than the other two groups but the difference was not significant.

The average study duration and the number of clinical and MRI assessments were similar for all groups of patients. Clinically, 13 relapses occurred during the study period: 10 in six relapsing remitting patients of whom three had one relapse, two patients two

Table 1 Baseline clinical and MRI data

\begin{tabular}{|c|c|c|c|c|}
\hline & Relapsing remitting & Secondary progressive & Primary progressive & Pvalue \\
\hline No of patients & 9 & 9 & 10 & \\
\hline Mean age $(y)$ & $29 \cdot 6(6 \cdot 5)(22-45)$ & $41 \cdot 4(6 \cdot 7)(30-50)$ & $42 \cdot 1(5 \cdot 8)(33-50)$ & 0.001 \\
\hline $\operatorname{Sex}(M / F)$ & $0: 9$ & $4: 5$ & $9: 1$ & $0 \cdot 001$ \\
\hline Mean age of disease onset (y) & $25 \cdot 2(7 \cdot 5)(16-43)$ & $31(3 \cdot 3)(28-37)$ & $31 \cdot 1(5 \cdot 3)(25-39)$ & NS \\
\hline Mean disease duration $(\mathrm{y})$ & $4 \cdot 3(1 \cdot 6)(2 \cdot 2-6 \cdot 8)$ & $10 \cdot 3(5 \cdot 7)(1 \cdot 6-22 \cdot 3)$ & $10 \cdot 9(5 \cdot 4)(5 \cdot 2-21 \cdot 8)$ & 0.009 \\
\hline \multicolumn{5}{|l|}{ Baseline EDSS } \\
\hline $0-2 \cdot 5$ & $56 \%$ & $0 \%$ & $0 \%$ & \\
\hline $3 \cdot 0-5 \cdot 5$ & $44 \%$ & $22 \%$ & $50 \%$ & \\
\hline$\geqslant 5 \cdot 5$ & $0 \%$ & $78 \%$ & $50 \%$ & 0.001 \\
\hline Mean progression index & $0.62(0.44)(0-1.4)$ & $0.97(1.09)(0.3-3.5)$ & $0.54(0.16)(0.2-1.2)$ & NS \\
\hline Mean baseline MRI lesion load & $72 \cdot 8(80 \cdot 9)(3-246)$ & $81 \cdot 8(48 \cdot 6)(25-164)$ & $41 \cdot 7(50 \cdot 5)(0-172)$ & NS \\
\hline
\end{tabular}

Values in parentheses are (SD) (range). 
Figure 1 Scatter plots of serial data for relapsing remitting $(n=9)$, secondary progressive $(n=$ 9), and primary progressive $(n=10)$ patients with multiple sclerosis. For comparative purposes each patient's position on the horizontal axis is maintained from figure $1 \mathrm{~A}$ to $1 C$; solid vertical lines link all serial data points for a particular patient. Horizontal dashed lines represent 3 SDs above the mean of the controls and the shaded area the normal range. (A) Number of gadolinium-enhancing lesions per MRI study of the brain and spinal cord. (B) Soluble E-selectin $(\mathrm{ng} / \mathrm{ml})$. (C) $C$ reactive protein $(\mathrm{mg} / \mathrm{l})$.
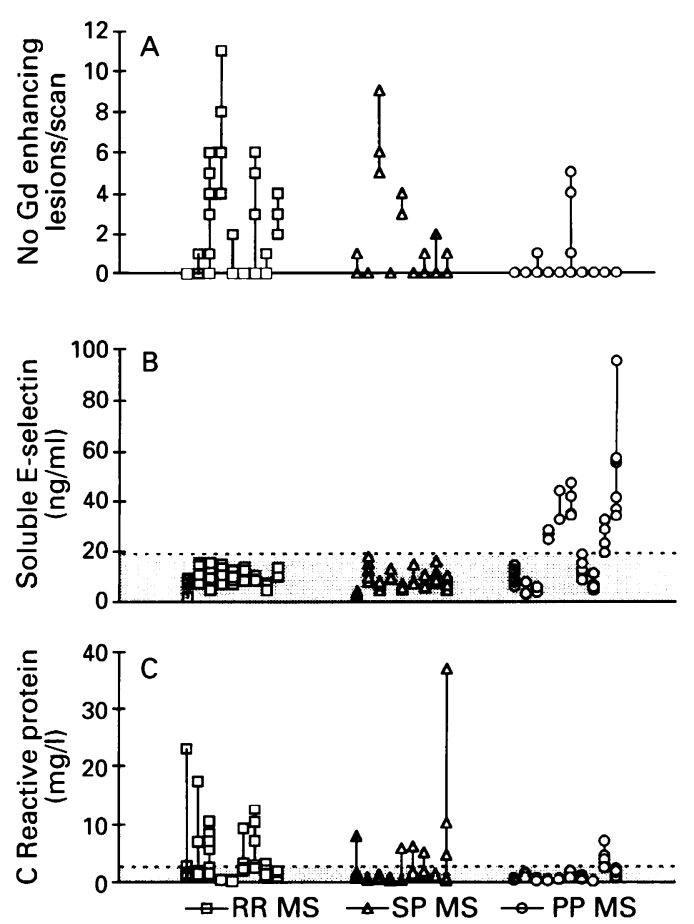

relapses, and one patient three relapses. The three relapses in the secondary progressive group occurred in two patients. Five of the relapsing remitting patients were recruited during a relapse and improved clinically during the study accounting for the lower median exit EDSS of 2 compared with 2.5 at entry. None of the patients with relapses were treated with corticosteroids. The clinical onset of the 13 relapses occurred with a median of seven (range 2-42) days before the initial or follow up clinical and MRI examination. One of the primary progressive patients, with normal $\mathrm{sE}$ selectin concentrations and no MRI activity, was on a continuous low dose of oral prednisone (10 to $40 \mathrm{mg}$ per day) for the duration of the study period. No other patient received immunosuppressive treatment. Six symptomatic infective episodes occurred in five patients in the week preceding or at the time of an MRI assessment. These occurred in one secondary progressive and four relapsing remitting patients. Two of the infections involved the urinary tract and the remainder the upper respiratory tract. No primary progressive patients had symptomatic infections during the period defined above. Activity on MRI assessed by Gd enhancement was detected at some time during the study period in seven of nine relapsing remitting, six of nine secondary progressive, and in only two of 10 primary progressive patients $(P=0.03$, fig 1A). The mean number of active lesions per scan was similar in relapsing remitting and secondary progressive patients but significantly less in the primary progressive group ( $\mathrm{P}$ $=0.04)$. Nine of the $13(69 \%)$ clinical relapses were associated with MRI activity compared with only $37(27 \%)$ out of the other 139 follow up examinations $(P=0.03)$.

SERUM MARKERS (TABLE 2)

Soluble E-selectin concentrations were significantly higher in primary progressive compared with relapsing remitting or secondary progressive patients $(P=0.03$, fig $1 \mathrm{~B})$. This increase was moderate compared with mean sEselectin concentrations of 86 (range 45-147) $\mathrm{ng} / \mathrm{ml}$ in 11 patients with active rheumatoid arthritis, measured with our assay. The increase in the primary progressive group could be attributed to five patients with persistently raised $\mathrm{sE}$-selectin concentrations throughout the study period. These five patients seemed to be clinically more progressive during the study period, deteriorating on average 1.4 EDSS points/year compared with an average of $0.4 \mathrm{EDSS}$ points/year in patients with low sE-selectin concentrations. This was not statistically significant. Mean concentrations of sE-selectin did not correlate with MRI activity, clinical relapse, or infectious episodes. There was no difference in MRI activity between the five primary progressive patients with raised sE-selectin concentrations $(>3 \mathrm{SD}$

Table 2 Follow up clinical and MRI data

\begin{tabular}{|c|c|c|c|c|}
\hline & Relapsing remitting & Secondary progressive & Primary progressive & Pvalue \\
\hline \multicolumn{5}{|l|}{ Mean duration of } \\
\hline Mean No of scans/patient & $6 \cdot 9(1.4)(5-9)$ & $5 \cdot 2(1 \cdot 8)(3-8)$ & $5 \cdot 0(2 \cdot 1)(2-8)$ & NS \\
\hline \multicolumn{5}{|l|}{ Exit EDSS } \\
\hline $0-2 \cdot 5$ & $56 \%$ & $0 \%$ & $0 \%$ & \\
\hline $3 \cdot 0-5 \cdot 5$ & $44 \%$ & $11 \%$ & $30 \%$ & 0.001 \\
\hline$\geqslant 5 \cdot 5$ & $0 \%$ & $89 \%$ & $70 \%$ & \\
\hline No of relapses & 10 & 3 & 0 & 0.003 \\
\hline & \multicolumn{2}{|c|}{ Mean No Gd enhancing } & 0 & NS \\
\hline lesions/scan & $1 \cdot 7(2 \cdot 2)(0-6 \cdot 7)$ & $1.03(1 \cdot 7)(0-5)$ & $0 \cdot 28(0.79)(0-2 \cdot 5)$ & $0 \cdot 04$ \\
\hline \multicolumn{5}{|l|}{$\begin{array}{l}\text { Activity (No Gd enhancing } \\
\text { lesions/scan) }\end{array}$} \\
\hline 0 & $22 \%$ & $33 \%$ & $80 \%$ & \\
\hline $0-1$ & $34 \%$ & $45 \%$ & $10 \%$ & \\
\hline $1-1.9$ & $22 \%$ & $0 \%$ & $0 \%$ & NS \\
\hline $2-2 \cdot 9$ & $0 \%$ & $0 \%$ & $10 \%$ & \\
\hline $3-3 \cdot 9$ & $11 \%$ & $11 \%$ & $0 \%$ & \\
\hline$\geqslant 4$ & $11 \%$ & $11 \%$ & $0 \%$ & \\
\hline \multicolumn{5}{|l|}{ Mean soluble E-selectin } \\
\hline \multirow{2}{*}{$\begin{array}{l}\text { Mean } C \text { reactive protein } \\
(\text { normal }=0.78(0.65) \mathrm{mg} / \mathrm{l})\end{array}$} & $9 \cdot 8(2 \cdot 0)(6 \cdot 2-12 \cdot 2)$ & $7 \cdot 7(2 \cdot 7)(3 \cdot 6-10 \cdot 8)$ & $22 \cdot 2(16 \cdot 1)(5 \cdot 3-53 \cdot 7)$ & 0.03 \\
\hline & $3 \cdot 16(2 \cdot 54)(0 \cdot 13-7 \cdot 11)$ & $2 \cdot 28(2 \cdot 21)(0 \cdot 48-7 \cdot 7)$ & $1.03(1.14)(0.14-3.97)$ & 0.03 \\
\hline $\begin{array}{l}\text { Mean von Willebrand factor } \\
(\text { normal }=1.26(0.41) \mathrm{IU} / \mathrm{ml})\end{array}$ & $1 \cdot 10(0.29)(0.55-2 \cdot 87)$ & $1.44(0.25)(1.09-1.8)$ & $1.33(0.72)(0.55-2.87)$ & NS \\
\hline $\begin{array}{l}\text { Mean tumour necrosis factor } \alpha \\
\quad(\text { normal }=16 \cdot 4(8 \cdot 3) \mathrm{pg} / \mathrm{ml})\end{array}$ & $14 \cdot 7(7 \cdot 1)(8 \cdot 8-29 \cdot 8)$ & $17 \cdot 8(6 \cdot 9)(11 \cdot 1-28 \cdot 3)$ & $51 \cdot 2(58 \cdot 9)(12 \cdot 7-154 \cdot 2)$ & NS \\
\hline
\end{tabular}

Values in parentheses are (SD) (range). 
Figure 2 Scatter plot of the transformed mean plasma TNFa and serum sE-selectin concentrations, with a linear regression line and correlation coefficient, for nine relapsing remitting, six secondary progressive, and nine patients with primary progressive multiple sclerosis, and 10 normal control subjects.

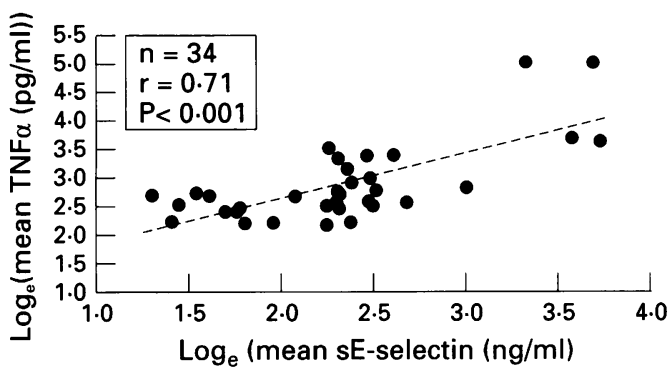

above the norm) and the primary progressive patients with normal sE-selectin concentrations (data not shown).

By contrast CRP was intermittently raised relative to our normal range in several relapsing remitting and secondary progressive patients during the study (fig $1 \mathrm{C}$ ), resulting in the means of the individual relapsing remitting or secondary progressive patients being significantly higher than the primary progressive patients $(P=0.03)$. With the caveat that individual CRP measurements may not be independent of each other, episodes of raised CRP were commonly associated with infectious episodes, clinical relapse, and MRI activity. The mean CRP of the normal controls was 0.8 (SD 0.65$) \mathrm{mg} / \mathrm{l}$, and this was significantly lower than the concentrations found during infectious episodes $(5.59$ (SD $4 \cdot 16) \mathrm{mg} / \mathrm{l}, \mathrm{P}<$ $0.001)$, during a clinical relapse $(4.02$ (SD $6.39) \mathrm{mg} / \mathrm{l}, \mathrm{P}=0.004$ ) and those associated with disease activity on MRI (3.37 (SD $6.23) \mathrm{mg} / \mathrm{l}, \mathrm{P}<0.001)$. The $\mathrm{CRP}$ measurements associated with active MRI studies were significantly higher than the concentrations associated with inactive scans (3.37 (SD 6.23) $\mathrm{mg} / \mathrm{l} v 1.47(\mathrm{SD} 1.74) \mathrm{mg} / \mathrm{l}, \mathrm{P}=0.04)$ The CRP concentrations of these patients with inactive studies without infections or clinical relapse, were significantly higher than the normal controls $(1.47$ (SD 1.74) mg/l v 0.78 (SD $0.65) \mathrm{mg} / \mathrm{l}, \mathrm{P}=0.004)$. Despite the above differences, CRP concentrations had a very poor predictive value of disease activity, with only $39 \%$ of clinical relapses and $22 \%$ of active MRI studies being associated with a raised CRP ( $>3$ SD above the norm). From figs 1B and $1 \mathrm{C}$ it is apparent that patients with episodes of raised CRP concentrations had associated low sE-selectin concentrations, and only one patient with raised sE-selectin concentrations (primary progressive patient 9 , fig 1C) had a slightly raised mean CRP concentration.

Serum vWF tended to be slightly higher in secondary progressive patients, but it did not reach a statistically significant value in any of the patient groups. Concentrations of vWF did not correlate with clinical relapse, MRI activity, or sE-selectin concentrations.

Plasma TNF $\alpha$ concentrations were not availabe for one primary progressive and three secondary progressive patients. Primary progressive patients tended to have higher plasma TNF $\alpha$ concentrations than the relapsing remitting and secondary progressive patients, but this did not reach statistical significance. However, mean plasma concentrations of
TNF $\alpha$ did correlate with mean serum concentrations of sE-selectin over the study period ( $\mathrm{n}=34, r=0.71$ and $\mathrm{P}<0.001 ;$ fig 2 ). Concentrations of TNF $\alpha$ did not correlate with MRI activity, clinical relapse, disease progression, CRP concentration, or vWF concentrations (data not shown).

\section{Discussion}

The baseline characteristics of the patients in our study confirm the different clinical and radiological features of the previously described clinical subtypes of multiple sclerosis. ${ }^{16}$

Multiple sclerosis lacks a practical and reliable immunological marker of disease activity, and MRI is currently the most widely used technique for monitoring disease activity. ${ }^{22}$ Our results suggest that for patients with relapsing remitting or secondary progressive disease, sE-selectin is not a useful marker of disease activity; sE-selectin concentrations in these patients correlated with neither clinical relapse or MRI activity. However, in the smaller subgroup of patients with primary progressive multiple sclerosis, $\mathrm{sE}$-selectin concentrations were raised. These findings are in agreement with the those of Dore-Duffy and colleagues, ${ }^{23}$ who found significantly raised sEselectin concentrations in chronic progressive patients compared with those with stable or relapsing remitting courses. This suggests that sE-selectin may be a useful indicator of activity in some patients with progressive multiple sclerosis, a group in whom MRI is much less useful because of the characteristically low frequency with which new lesion formation and blood-brain barrier leakage are seen. Furthermore, these findings add to the growing body of evidence from genetic, ${ }^{24-27}$ epidemiologi$\mathrm{cal}^{28}{ }^{28}$ radiological, ${ }^{16}$ and pathological ${ }^{29}$ studies, which point to a major difference in the pathophysiology of primary progressive multiple sclerosis in comparison with relapsing remitting forms of the disease.

Rieckmann et al in a serial study of 29 patients with multiple sclerosis followed up over 12 months $^{30}$ and Mobner et al in a cross sectional study including a subgroup of patients with multiple sclerosis, ${ }^{31}$ report similar findings to ours, with relapsing remitting patients having normal sE-selectin concentrations, despite evidence of disease activity. This finding of normal sE-selectin in the presence of perivascular inflammation may imply that insufficient endothelium is activated or that it is possibly activated for too short a time to release sufficient $s E$-selectin into the circulation. A possible threshold surface area of endothelium may need to be activated to result in a raised sE-selectin concentration. Also the window of E-selectin expression in stimulated endothelial monolayer cultures is from $24-48$ hours, ${ }^{7}$ and this may be too short to be detected in vivo. Another aspect that needs consideration is the natural ligands of sE-selectin, sialyl-Lewis ${ }^{\mathrm{x}}$ and sialyl-Lewis ${ }^{\mathrm{a}}$, on circulating leucocytes, ${ }^{32}$ as any increase in their expression would decrease the $\mathrm{sE}$ - 
selectin concentration proportionately. Another possibility is the inhibition of endothelial $\mathrm{sE}$-selectin expression despite the presence of proinflammatory cytokines known to induce sE-selectin production. Transforming growth factor- $\beta$ (TGF $\beta$ ), a potent inhibitor of E-selectin expression, ${ }^{33}$ is increased in patients with multiple sclerosis during regression of a relapse ${ }^{34}$ and increases in TGF $\beta$ producing lymphocytes are found in the CSF and circulation of patients with relapsing remitting multiple sclerosis. ${ }^{35}$ An increased expression of TGF $\beta$ in and around blood vessels of acute multiple sclerosis plaques has also been described. ${ }^{36}$ Thus TGF $\beta$ may be inhibiting E-selectin expression in this group of patients. An interesting finding was the dichotomy in the primary progressive patients, with half the patients having persistently raised concentrations of sE-selectin. This may suggest that these primary progressive patients have more diffuse or ongoing endothelial activation, or that they produce insufficient quantities of TGF $\beta$ to inhibit $\mathrm{E}$ selectin expression. A functional lack of TGF $\beta$ may explain the progressive non-remitting course of the primary progressive patients as $\mathrm{TGF} \beta$ seems to be important in inducing remission. The factor has also been shown to improve acute ${ }^{37}$ and chronic relapsing experimental allergic encephalomyelitis. ${ }^{38} 39$ The close correlation between sE-selectin and TNF $\alpha$ concentrations is not suprising, as TNF $\alpha$ induces E-selectin expression, ${ }^{7}$ and this correlation has been described in Kawasaki's disease $^{40}$ and malaria. ${ }^{41}$

The finding of modestly raised CRP concentrations during some relapses and in association with MRI activity confirms earlier reports of raised CRP concentrations in patients with multiple sclerosis during relapse. ${ }^{42} 43$ An interesting finding was the significantly raised CRP concentrations in patients with inactive MRI compared with controls that could not be explained by infection, implying the presence of active inflammation that is either not associated with Gd enhancement or is below the spatial resolution of the MRI protocol used in this study. This finding supports a pathological study in which the number of histologically active lesions far exceeded the number detected by postmortem T2 weighted $\mathrm{MRI} .{ }^{44} \mathrm{C}$ Reactive protein is synthesised by the liver mainly in response to IL6, and augmented by $\mathrm{TNF} \alpha$, IL 1 , and leukaemia inhibitory factor (LIF). ${ }^{45}$ The primary progressive patients did not have raised CRP concentrations despite half of them having evidence of endothelial activation due to ILl and $\mathrm{TNF} \alpha$, as well as detectable concentrations of circulating TNF $\alpha$. This implies focal activity of these cytokines without the hepatic endocrine effects that result in the acute phase response. Interestingly TGF $\beta$ has a facilitatory role on the systemic acute phase response induced by IL1 and TNF $\alpha{ }^{45}$ despite inhibiting their effects on endothelial expression of E-selectin. ${ }^{33}$

The finding of normal vWF concentrations implies that significant endothelial damage is unlikely to occur in multiple sclerosis. This is by contrast with idiopathic uveoretinitis, an inflammatory disease of the eye (an immune privileged site similar to the CNS in multiple sclerosis ${ }^{46}$ ), in which raised concentrations of vWF have been described. ${ }^{47}$ The lack of correlation between vWF and sE-selectin concentrations is not suprising, as the release of vWF by endothelial cells, unlike sE-selectin, is not primarily induced by proinflammatory cytokines, and requires additional stimuli-for example, thrombin. ${ }^{48}$

In summary, sE-selectin concentrations did not correlate with lesion enhancement on MRI and were therefore not increased in patients with relapsing remitting or secondary progressive multiple sclerosis. Surprisingly, half the primary progressive patients who tended to have more progressive disease without lesion enhancement on MRI, had raised concentrations which were closely correlated with plasma concentrations of TNF $\alpha$. By contrast, an acute phase response, as measured by CRP, was present in relapsing remitting and secondary progressive but not primary progressive patients, and was associated with MRI activity and clinical relapse. This highlights immunological differences between patient groups, and provides some clue to the possible nature of progressive disability in patients with primary progressive multiple sclerosis. In addition to confirmation of our findings, studies need to be performed to further elucidate the nature of these differences. Insights obtained from these studies would allow a rational approach to the treatment of patients with progressive multiple sclerosis.

This work was supported by a grant from the Multiple Sclerosis Society of Great Britain and Northern Ireland.

1 Kermode AG, Thompson AJ, Tofts P, et al. Breakdown of the blood-brain barrier precedes symptoms and other MRI signs of new lesions in multiple sclerosis. Brain 1990;113:1477-89.

2 Hawkins CP, Munro PMG, Mackenzie F, et al. Duration and selectivity of blood-brain barrier breakdown in chronic relapsing experimental allergic encephalomyelitis chronic relapsing experimental allergic encephalomyelitis studied by gadolini

3 Katz D, Taubenberger JK, Cannella B, et al. Correlation between magnetic resonance imaging findings and lesion development in chronic, active multiple sclerosis. Ann Neurol 1993;34:661-9.

4 Rodriguez M, Scheithauer BW, Forbes G, Kelly PJ. Oligodendrocyte injury is an early event in lesions of multiple sclerosis. Mayo Clin Proc 1993;68:627-36.

5 Hauser SL, Bhan AK, Gilles F, et al. Immunohistochemical analysis of the cellular infiltrate in multiple sclerosis lesions. Ann Neurol 1986;19:578-87.

6 Antel JP, Owens T. The attraction of adhesion molecules. Ann Neurol 1993;34:123-4.

7 Bnn Neurol 1993;34:123-4. Ann Rev Immunol 1993;11:767-804.

8 Lobb RR, Chirosso G, Leone, DR, et al. Expression and functional characterisation of a soluble form endothelial leukocyte adhesion molecule-1. F Immunol 1991;147 124-9.

9 Gearing JH, Newman W. Circulating adhesion molecules in disease. Immunol Today 1993;14:5067.

10 Hartnung H-P, Reiners K, Michels $M$, et al. Serum level of soluble E-selectin (ELAM-1) in immune-mediate neuropathies. Neurology 1994;44:1153-8.

11 Oka N, Akiguchi I, Kawasaki T, et al. Elevated serum levels of endothelial leukocyte adhesion molecules in GuillainBarré syndrome and chronic inflammatory demyelinating polyneuropathy. Ann Neurol 1994;35:621-24.

12 Brinkhous KM, Sulzer DL, Reddick RL et al. Elevated plasma von Willebrand factor levels as an index of acute endothelial injury: use of a hypotonic injury model in rats. Federation Proceedings 1980;39:630.

13 Nusinow SR, Federici AB, Zimmerman TS et al. Increased von Willebrand factor antigen in the plasma of vasculitis. von Willebrand factor antigen in the
Arthritis Rheum 1984;27:1405-10.

14 Porta M, Townsend C, Clover GM et al. Evidence of functional endothelial cell damage in early diabetic retinopa- 
thy Diabetologica $1981 ; 20: 597-601$.

15 Poser CM, Paty DW, Scheinberg L, et al. New diagnostic criteria for multiple sclerosis: guidelines for research protocols. Ann Neurol 1983;13:227-31.

16 Thompson AJ, Kermode AG, Wicks D, et al. Major differences in the dynamics of primary and secondary progressive multiple sclerosis. Ann Neurol 1991;29:53-62.

17 Kurtzke JF. Rating neurologic impairment in multiple sclerosis: an expanded disability status scale (EDSS) Neurology 1983;33:1444-52.

18 Poser S, Raun NE, Poser W. Age at onset, initial symptomatology and course of multiple sclerosis. Acta Neurol Scand 1982;66:355-62.

19 Leeuwenberg JFM, Smeets EF, Neefjes J, et al. E-selectin and intercellular adhesion molecule-1 are released by and intercellular adhesion molecule-1 are released by activated human

20 Sharief MK, Hentges R. Association between tumour necrosis factor- $\alpha$ and disease progression in multiple sclerosis. N Engl F Med 1991;325:467-72.

21 Riches P, Gooding R, Millar BC, Rowbottom AW Influence of collection and separation of blood samples on plasma IL-1, IL- 6 and TNF- $a$ concentrations. $f$ Immunol Methods 1992;153:125-31.

22 Miller DH, Barkhof F, Berry I, et al. Magnetic resonance imaging in monitoring the treatment of multiple sclerosis: concerted action guidelines. $\mathcal{F}$ Neurol Neurosurg Psychiatry 1991;54:683-8.

23 Dore-Duffy P, Newman W, Balabanov R, et al. Circulating soluble adhesion proteins in cerebrospinal fluid and soluble adhesion proteins in cerebrospinal fluid and serum of patients with multiple sclerosis: co

24 Van Lambalgen R, Sanders EACM, D'Amaro J. Distribution, age of onset and HLA profiles in two types of multiple sclerosis. $\mathcal{F}$ Neurol Sci 1986;76:13-21.

25 Madigand M, Oger JJ-f, Fauchet R, et al. HLA Profiles in multiple sclerosis suggest two forms of disease and the existence of protective haplotypes. F Neurol Sci 1982;53 519-29.

26 Olerup O, Hillert J, Olsson T, et al. Primarily chronic progressive and relapsing/remitting multiple sclerosis: Two immunogenetically distinct disease entities. Proc Nat Acad Sci USA 1989;86:7113-7.

27 Hillert J, Grönning M, Nyland H, et al. An immunogenetic heterogeneity in multiple sclerosis. $\mathcal{f}$ Neurol Neurosurg heterogeneity in multiple

28 Larsen JP, Kvaale G, Riise T, et al. Multiple sclerosismore than one disease? Acta Neurol Scand 1985;72. 145-50.

29 Revesz T, Kidd D, Thompson AJ, et al. A comparison of the pathology of primary and secondary progressive multiple sclerosis. Brain 1994;117:759-65.

30 Rieckmann P, Martin S, Weichselbraun I, et al. Seria analysis of circulating adhesion molecules and the TNF receptor in serum from patients with multiple sclerosis: cICAM-1 is an indicator of relapse. Neurology 1994, 44:2367-72.

31 Mobner R, Fassbender K, Schwartz A, Hennerici $M$. Vascular cell adhesion molecule-a novel approach to detect endothelial cell activation in MS in vivo. 7 Neurol 1994;241 (suppl 1):S89-90.

32 Ishikawa $\mathrm{T}$ Imura A, Tanaka $\mathrm{K}$, et al. E-selectin and vascular cell adhesion molecule-1 mediate adult $\mathrm{T}$-cell leukemia cell adhesion to endothelial cells. Blood 1993 82:1590-8.

33 Gamble JR, Khew-Goodall Y, Vadas MA. Transforming growth factor- $\beta$ inhibits $E$-selectin expression on human endothelial cells. $\mathcal{F}$ Immunol 1993;1 150:4494-503.

34 Beck J, Rondot $\mathrm{P}$, Jullien $\mathrm{P}$, et al. TGF- $\beta$-like activity produced during regression of exacerbations in multiple sclerosis. Acta Neurol Scand 1991;84:452-5.

35 Link J, Fredrikson S, Södersteröm M, et al. Organ-specific autoantigens induce transforming growth factor- $\beta$ $m$ RNA expression in mononuclear cells in multiple sclerosis and myasthenia gravis. Neurology 1994;44:728-34.

36 Raine CS, Canella B. Multiple sclerosis: adhesion molecule and cytokine profiles in lesions of different ages. Neurology 1994;44:556S.

37 Racke MK, Cannella B, Albert P, et al. Evidence of endogenous regulatory function of transforming growth factor- $\beta 1$ in experimental allergic encephalomyelitis. In Immunol 1992;4:615-20.

38 Racke MK, Sriram S, Carlino J, et al. Long-term treatment of chronic relapsing experimental allergic encephalomyelitis by transforming growth factor- $\beta 2$. Neuroimmunol 1993;46:175-84.

39 Kuruvilla AP, Shah R, Hochwald GM, et al. Protective effect of transforming growth factor $\beta 1$ on experimental diseases in mice. Proc Natl Acad Sci USA 1991;88: 2918-21.

$40 \mathrm{Kim} \mathrm{DS}$, Lee KY. Serum-soluble E-selectin levels in Kawasaki-disease. Scand 7 Rheum 1994;23:283-6.

41 Santosneto $L$ Muniziunqueira M, Tosta CE. Severe cases of Plasmodium falciparum malaria show increased plasma levels of both E-selectin and tumour necrosis facto alpha. Clin Res 1994;42:A283.

42 Dowling PC, Cook SD. Disease markers in acute multiple sclerosis. Arch Neurol 1976;33:668-70.

43 Schuller E, Allinquant B. Determination of C-reactive protein by electroimmunodiffusion in blood and CSF of neurological patients. Eur Neurol 1973;9:216-33.

44 Newcombe J, Hawkins CP, Henderson CL, et al. Histopathology of multiple sclerosis lesions detected by magnetic resonance imaging in unfixed postmortem central nervous tissue. Brain 1991;114:1013-23.

45 Baumann $\mathrm{H}$, Gauldie J. The acute phase response. Immunol Today 1994;15:74-80.

46 Cserr HF, Knopf PM. Cervical lymphatics, the blood-brain barrier and the immunoreactivity of the brain: a new barrier and the immunoreactivity of

47 Zaman AG, Edelstein C, Stanford MR, et al. Soluble intercellular adhesion molecule-1 (sICAM-1) as a marker of disease relapse in idiopathic uveoretinitis. Clin Exp Immunol 1994;95:60-5.

48 Paleolog EM, Carew MA, Pearson JD. Effects of tumour necrosis factor and interleukin-1 on von Willebrand factor secretion from human vascular endothelial cells. Int $f$ Radiat Biol 1991;60:279-85. 